\title{
Evaluation of Scientific Advertisements of Pharmaceutical Products as Per UCPMP Guidelines
}

\author{
Preeti Patil, Virendra Siddharam Ligade, Pradeep Manohar Muragundi* \\ Department of Pharmacy Management, Manipal College of Pharmaceutical Sciences, Manipal University, Manipal-576104, Karnataka, INDIA.
}

\begin{abstract}
Background: Uniform Code for Pharmaceutical Marketing Practices (UCPMP), issued by the Department of Pharmaceuticals, introduced in India after several years of deliberations. The UCPMP is to be voluntarily adopted and implemented by pharmaceutical companies. The main aim of study was to evaluate the scientific advertisements of pharmaceutical products as per uniform code of pharmaceutical marketing practices (UCPMP) draft guidelines Methodology: Printed copies of the journals in Manipal University Health Sciences Library were scrutinised to identify Indian journals containing advertisements. All the selected journals published during the time period from Jan, 2012 to Dec, 2014 were further scrutinised to identify advertisements for evaluation. All the selected advertisements were evaluated for its content as per the UCPMP guidelines and the observations were recorded in the data collection sheet prepared for the study. The collected data was coded and entered into SPSS software. The results are presented in the form of descriptive statistic. Results: Some parameters such as claims-safe (85.9\%), no side effect (98.9\%), no toxic hazards $(99.2 \%)$, word new $(96.3 \%)$, brand name of competitors $(99.6 \%)$, name and address of company $(93.8 \%)$, method of administration $(71 \%)$, method of use $(88 \%)$, additional information on request $(65.5 \%)$
\end{abstract}

and name and photo of healthcare professionals (97.9\%) for full ads almost adhere to guidelines. Whereas some parameter such as claims without references $(56.8 \%)$, date of advertisement $(25.3 \%)$, adverse reaction, warnings, precaution for use and contraindications $(50.2 \%)$, recommended dose (55.6\%) for full ads do not follow guidelines. Conclusion: The present study has clearly shown the discrepancies in the usage of references for the substantiation of claims made and recommended dose.

Key words: UCPMP Guidelines, India, Scientific Advertisements, Journal, Claims, Pharmaceutical Marketing.

\section{Correspondence :}

Dr Pradeep Manohar Muragundi, MPharm., PhD., Assistant Professor-Selection Grade, Department of Pharmacy Management, Manipal College of Pharmaceutical Sciences, Manipal University, Manipal-576104, INDIA

Phone:+919880377572

Email: muragundi@hotmail.com

DOI: $10.5530 /$ jyp.2017.9.78

\section{INTRODUCTION}

Pharmaceutical advertising in medical journals is one of the main sources used by pharmaceutical companies to promote information of their products to physicians. Medical journals are regarded as a leading source of information for new drugs. They may also modulate the prescribing behavior of physicians without their knowledge. ${ }^{1}$ Journal advertisements attract physicians' attention because they are visually appealing. ${ }^{2}$ This may be one of the ways of getting scientific and educational information and keeping up-to-date with newly marketed drugs. Hence information provided in these journal advertisements should be of high quality to enable doctors to practice evidence-based medicine. However, it is been observed that the information provided in medical drug advertisements is often exaggerated, inaccurate and missing critical information on safe prescribing. ${ }^{3}$ Advertisements which exaggerate the benefits and downplay the risk of a drug, with poorly supported claims, failing to balance claims of efficacy with potential adverse effects, and promoting a drug for groups other than those for whom it is approved, are likely to adversely affect treatment. ${ }^{3}$ While some evidence indicates that promotion may adversely influence prescribing, physicians hold a wide range of views about pharmaceutical promotion. ${ }^{4}$ The transparency of pharmaceutical advertisements is important for 2 reasons: First, there is evidence that physician prescribing is influenced by pharmaceutical advertisements. Second, the pharmaceutical industry views advertisements as one way in which they can educate physicians. Given the potential for misrepresentation, health care professionals should be able to examine the cited references to determine whether the manufacturer's claims are justified.
The presence of stringent government regulations on citation is particularly important as it helps individual clinicians and groups (e.g., hospital pharmacy and therapeutics committees) to obtain cited documents to determine whether a claim is adequately substantiated. ${ }^{5}$ There are three major codes which deal with the promotion of drugs: the International Federation of Pharmaceutical Manufacturers (IFPMA) code of pharmaceutical marketing practices; the World Health Organization's ethical criteria for medical drug promotion; and the code prepared by Health Action International. However, despite the availability of regulations worldwide, pharmaceutical advertising in a medical journal has been criticized for being of poor quality. ${ }^{6}$ The quality control systems adopted by government's pharmaceutical companies and industry association for evaluation of promotional materials and ethical interactions exist in India at national and individual level. ${ }^{7}$ In general, there are two types of regulations like Government Regulations and Self-regulations which are used to control the promotional aspects of pharmaceutical drugs.

The Department of Pharmaceuticals under the Union Ministry of Chemical and Fertilizers presented a draft, voluntary code of conduct for the drug industry. The UCPMP was proposed as self-regulating code in March 2012 asking all the companies to implement and submit the report to the government. The UCPMP was up on the departments' website for inviting comment from all the stakeholders. The comments received were examined and final draft UCPMP was prepared and circulated to Pharm associations for their comments. 


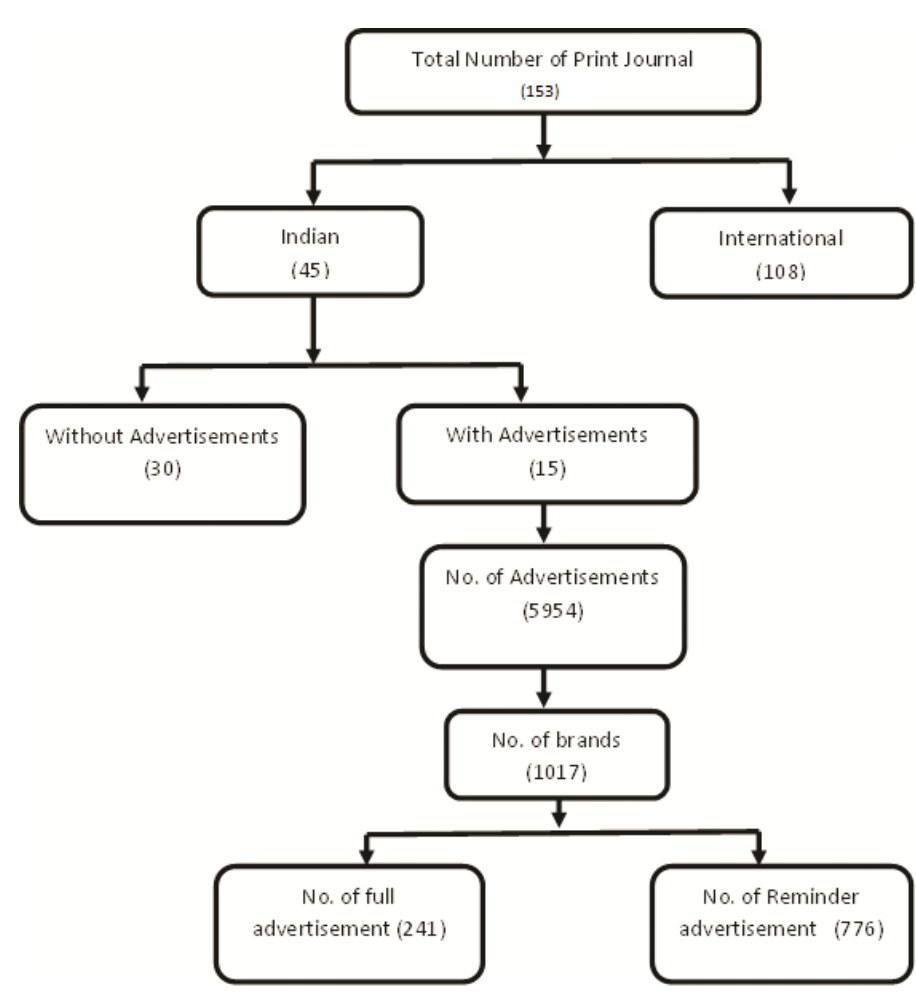

Figure 1: Scheme for selection of Journals containing advertisements

As per UCPMP guidelines the promotional materials such as Journal advertisements and mailers must not be designed to disguise their real nature and should contain basic minimum information as mentioned in the code. Names and Photograph of the healthcare professionals should not be used in the promotional materials.

Organization of Pharmaceutical Producers of India (OPPI) has urged the government to make its Uniform Code for Pharmaceutical Marketing Practices (UCPMP) a statutory code in the best interests of patients and the industry. By doing so will lead to a higher level of accountability and transparency and removes all confusions among industry, health care

\section{Table 1: List of Indian Journals containing advertisements}

\begin{tabular}{cl}
\hline SI No. & \multicolumn{1}{c}{ Name of the Journal } \\
\hline 1 & Journal of the Indian Medical association \\
2 & Journal of the Association of Physician of India \\
3 & Indian Journal of Paediatrics \\
4 & Indian Paediatrics \\
6 & Indian Journal of Orthopaedics \\
7 & Indian Journal of Gastroenterology \\
8 & Indian journal of Obstetrics and Gynaecology of India \\
9 & Indian Journal of Dermatology \\
10 & Indian Journal Venerology and Leprosy \\
11 & Indian Journal of Cancer \\
12 & Indian Journal of Psychiatry \\
13 & Indian Journal of Urology \\
14 & Indian Journal of Sexually Transmitted Disease and Aids \\
15 & Antiseptic \\
\hline
\end{tabular}

professionals and patients. ${ }^{6}$ The present study was designed to evaluate the scientific advertisements of pharmaceutical products as per uniform code for pharmaceutical marketing practices (UCPMP) draft guidelines.

\section{METHOD}

Printed copies of the Medical journals available in Manipal University Health Sciences Library were scrutinized for the study. Further Medical journals which are published from India containing advertisements were selected. List of the medical journals containing advertisements are enlisted in Figure 1.

All the selected medical journals published during the time period of 3 years, from January 2012 to December 2014 were further scrutinized to identify advertisements for evaluation. All the selected advertisements were evaluated for the following content as per the UCPMP guidelines which are listed below

1. Claims and comparisons : The word "safe" should not be used without qualification and it must not be stated categorically that a medicine has

- No side effects

- No Toxic hazards

- No Risk of addiction

2. The word "New" must not be used to describe

- Any drug which is generally available

- Any therapeutic indication which is available in India for more than 12 months.

3. Comparisons must be fair, factual and substantiated

- Brand names of competitor companies must not be used without prior consent

4. Other companies, their products, or promotions must not be disparaged

5. Clinical, and/or scientific opinions of members of health care professionals must not be disparaged.

6. The printed matters should contain the following information

- Name and address of the company

- Name of drug and active ingredients with quantity

- Recommended dosage, method of use if not obvious, method of administration

- Adverse reactions, warnings and precautions for use and contraindications

- A statement that "additional information available on request"

- Date on which the above particulars were generated

7. The names or photographs of healthcare professionals must not be used

8. Must not imitate devices, copy slogans or general layouts of other companies

A Data collection sheet was prepared and used for collecting the data from the selected Journals. The collected data was coded and entered in to SPSS (Statistical Package for Social Sciences) software version 16.0. Data is presented in the form of descriptive statistic and results were presented in the form of tables.

For the purpose of study full advertisements are defined as the advertisements containing all the information required for prescribing the product and the one which also adheres to the requirements as per UCPMP guidelines. Reminder advertisements are the defined as the one which contain information relating to brand name, generic name, manufacturer's name and which serves the purpose of reminding the brand name to the prescriber. 
Table 2: Claims in the advertisements

\begin{tabular}{lcccc}
\hline \multirow{2}{*}{$\begin{array}{c}\text { Criteria } \\
\end{array}$} & $\begin{array}{c}\text { Compliance Status for Full Advertisements } \\
\text { (Percentage Frequency) }\end{array}$ & $\begin{array}{c}\text { Compliance Status for Reminder Advertisements } \\
\text { (Percentage Frequency) }\end{array}$ \\
\cline { 2 - 5 } & No & Yes & No & Yes \\
\hline Safe & 14.1 & 85.9 & 2.7 & 97.3 \\
No Side Effects & 1.2 & 98.8 & 0.8 & 99.9 \\
No Toxic Hazards & 0.8 & 99.2 & 0 & 100 \\
No Risk of Addiction & 1.7 & 98.3 & 0 & 100 \\
New & 3.7 & 96.3 & 0.8 & 99.2 \\
\hline
\end{tabular}

Table 3: Contents of Advertisements

\begin{tabular}{lcccc}
\hline \multirow{2}{*}{ Criteria } & \multicolumn{2}{c}{$\begin{array}{c}\text { Compliance Status for Full Advertisements } \\
\text { (Percentage Frequency) }\end{array}$} & $\begin{array}{c}\text { Compliance Status for Reminder Advertisements } \\
\text { (Percentage Frequency) }\end{array}$ \\
\cline { 2 - 5 } & No & Yes & No & Yes \\
\hline Brand names of competitors & 0.4 & 99.6 & 0 & 100 \\
Name and address of the company & 93.8 & 6.2 & 62.8 & 37.2 \\
Recommendation of dosage & 55.6 & 44.4 & 0.5 & 99.5 \\
Method of use if not obvious & 88 & 12 & 23.5 & 76.5 \\
Method of administration & 71 & 29 & 1.2 & 98.8 \\
\hline
\end{tabular}

Table 4: Substantiation of claims and visual contents

\begin{tabular}{lcccc}
\hline \multicolumn{1}{c}{ Criteria } & $\begin{array}{c}\text { Compliance Status for Full advertisements } \\
\text { (Percentage Frequency) }\end{array}$ & $\begin{array}{c}\text { Compliance Status for Reminder Advertisements } \\
\text { (Percentage Frequency) }\end{array}$ & Yes \\
\cline { 2 - 5 } & No & Yes & 73.8 & 26.2 \\
\hline Claims with references & 56.8 & 43.2 & 99.8 & 0.5 \\
$\begin{array}{l}\text { Date of preparation of } \\
\text { advertisements }\end{array}$ & 74.7 & 25.3 & & 0.3 \\
$\begin{array}{l}\text { Name and image of health care } \\
\text { professionals }\end{array}$ & 2.1 & 97.9 & & 99.7 \\
\hline
\end{tabular}

\section{RESULTS}

Out of 15 selected journals, there were 1017 brands with 5954 advertisements containing 776(76.3\%) reminder advertisements and 241(23.7\%) full advertisements. All parameters were evaluated as per guidelines and presented in tabulated form.

\section{a. Comparison of claims}

As per UCMCP guidelines if advertisements claim that the drug is safe, then the reference must be quoted. Table 2 shows that $85.9 \%$ of full advertisements adhere to guidelines and $14.1 \%$ do not follow it. And in reminder advertisements $97.3 \%$ adhere to guidelines, $98.9 \%$ full advertisements don't claim "no side effect" and in reminder advertisements, 99.9\% don't claim "no side effect", which means they adhere to guidelines. Almost 96.3\% full advertisements and 99.2\% reminder advertisements adhere to guidelines but still $3.7 \%$ of full advertisements are not following it.

\section{b. Contents of Advertisements}

Table 3 indicate that $99.6 \%$ full advertisements and $100 \%$ of reminder advertisements follow guidelines for use of brand names of competitor companies. As per guidelines, advertisements should mention name and address of the company. The results of the study clearly show that 93.8\% full advertisements adhere to guidelines and $6.2 \%$ violate it. But about $37.2 \%$ reminder advertisements are violating and $62.8 \%$ adhering to guidelines.

$55.6 \%$ advertisements give recommended dose but $44.4 \%$ advertisements do not give recommended dose which means some companies don't follow the guideline for this particular criteria. And in reminder advertisements, 99.5\% don't give dose which means it is adhering to it.

As per guidelines method of use of the particular drug should be mentioned. The results shown in Table 3 indicate that $88 \%$ of full advertisements are adhering to guidelines and about $12 \%$ do not follow it, and $23.5 \%$ of reminder advertisements are mentioning the method of use which is not required but $76.5 \%$ of as are following guidelines.

As per guidelines, full advertisements should contain a method of administration but the above results show that only $71 \%$ of full advertisements contain this information and remaining $29 \%$ do not give information for method of administration which means some companies do not follow guidelines for this clause. And in reminder advertisements, 98.8\% do not mention the method of administration which means they follow it.

\section{c. Precautionary and other information}

As per guidelines in full advertisements adverse reactions, warnings and precautions for use and contraindications should be mentioned but results of the study showed that only $49.8 \%$ advertisements contain this information and remaining $50.2 \%$ do not contain information which 
means most companies do not follow the clause mentioned in the guidelines. And 99.5\% reminder advertisements do not have information which means they are adhering to guidelines.

As per guidelines, full advertisements should mention "additional information available on request" but the results showed that $63.5 \%$ full advertisements mention it and $36.5 \%$ do not mention whereas reminder advertisements should not mention but $12.9 \%$ advertisements mention it.

\section{d. Substantiation of claims and visual contents}

Table 4 shows that only $43.2 \%$ of full advertisements adhere to guidelines and $56.8 \%$ of full advertisements violating it. And almost $73.8 \%$ reminder advertisements adhere to guideline and $26.2 \%$ do not follow it. $99.5 \%$ of reminder advertisements do not contain the date of advertisement whereas in full advertisement $25.3 \%$ advertisements give the date of advertisement but $74.7 \%$ do not give the date of advertisement which means it does not follow guidelines. Table 4 shows that in full advertisements $97.9 \%$ of advertisements don't contain name and image of healthcare professionals which is significant and in reminder advertisements, $99.7 \%$ of advertisements do not feature the image of healthcare professionals.

\section{DISCUSSION}

Due to the important role played by scientific advertisements in influencing the physicians in decision making they are regularly evaluated. There are many studies which evaluated the contents of these scientific advertisements in medical journals by using World Health Organization's ethical criteria for medical drug promotion. In a systematic review done by Othman $\mathrm{N}$ et.al., the major non-compliance was found in the area of claim substantiation using references, product information, validity of the claims made. ${ }^{8}$ The studies done in Indian context also found to have inadequate product information and had unsubstantiated claims. ${ }^{9-10}$

In the present study we used the newly drafted UCPMP guidelines for the content evaluation of the scientific advertisements of pharmaceutical products in selected medical journals. We found that the advertisements evaluated did not comply with name and address of the company sponsoring advertisement, recommended dose and method of administration in case of full advertisement category. Another very major area of concern was substantiation of claims with references. It was found that more than half of the full advertisements were making unsubstantiated claims. Even though reminder advertisements serve the purpose of reminding brand name for top of mind recall hence contain less content, we found that more than half the advertisements the name and address of the company was missing.

The noncompliance with regard to scientific advertisements in the area of contents and substantiated claims was a common thread among other studies which used non UCPMP guidelines and our study..

\section{CONCLUSION}

The available UCPMP guidelines provide a useful guidance for drug promotion in India. But in the case of pharmaceutical advertisements they have not mentioned whether guidelines have to be followed for full ads or for reminder ads. In this study, we evaluated both forms of advertisements. Full advertisements should contain all parameters mentioned in guidelines and reminder advertisements may contain only the brand name, generic name, and name and address of company advertising the drug. The study indicates a lack of adherence related to usage of the claim made, recommended dose, date of advertisement, adverse reaction, warnings, precautions and contraindications. To ensure complete information and ethical medicinal drug advertising in medical journals there is need of stringent mandatory regulations.

\section{Limitation of the study}

The study was limited to the advertisements found in the journals available physically in Manipal University Library. Hence the results may be gross representation of all the advertisements published in all the Indian Journal.

\section{Compliance with ethical standards}

No Funding received from any source from any of the authors

Ethical approval: not required as the study was not done on animals or humans and the data collection only involved secondary sources

Authors declare to have no competing interest

\section{ACKNOWLEDGEMENT}

Authors would like to acknowledge Manipal University Health Sciences Library for providing facilities to conduct the research.

\section{CONFLICT OF INTEREST}

Authors do not have any conflict of interest.

\section{ABBREVIATION USED}

UCPMP: Uniform Code for Pharmaceutical Marketing Practices; OPPI: Organisation of Pharmaceutical Producers of India; IFPMA: International Federation of Pharmaceutical Manufacturers.

\section{REFERENCES}

1. Gahalaut P, Chauhan S, Mishra N, Rastogi M, Thakur R. Drug advertisements in two dermatology journals: A critical comparison of IJDVL and JAAD. Indian Journal of Dermatology, Venereology, and Leprology. 2014;80(2):115. https://doi. org/10.4103/0378-6323.129381; PMid:24685846.

2. Politics of medicines. Analysing Pharmaceutical Advertisements in Medical Journals. http://www.politicsofmedicines.org/articles/analysing-pharmaceuticaladvertisements-in-medical-journals. Accessed Jan15, 2015.

3. Dhanaraj E, Nigam A, Bagani S, Singh H, Tiwari P. Supported and unsupported claims in medicinal drug advertisements in Indian medical journals. Indian Journal of Medical Ethics Vol VIII No 3 July-September 2011. https://doi.org/10.20529/ ijme.2011.067

4. Spurling GK, Mansfield PR, Montgomery BD, Lexchin J, Doust J, Othman N Vitry Al. Information from pharmaceutical companies and the quality, quantity, and cost of physicians' prescribing: a systematic review. PLoS Med. 2010;7(10):e1000352. https://doi.org/10.1371/journal.pmed.1000352 PMid:20976098 PMCid:PMC2957394

5. Cooper RJ, Schriger DL. The availability of references and the sponsorship of original research cited in pharmaceutical advertisements. Canadian Medical Association Journal. 2005;172(4):487-91. https://doi.org/10.1503/cmaj.1031940; PMid:15710940 PMCid:PMC548410.

6. Oshikoya KA, Senbanjo 1O, Soipe A. Adequacy of pharmacological information provided in pharmaceutical drug advertisements in African medical journals. Pharmacy practice. 2009;7(2):100. https://doi.org/10.4321/S188636552009000200006; PMid:25152785 PMCid:PMC4139747.

7. Muragundi PM, Ligade VS, Sreedhar D, Janodia MD, Udupa N. Regulatory Scenario of Pharmaceutical Marketing Practices in India. The Pharma Review. 2014:66-70

8. Othman N, Vitry A, Roughead EE. Quality of pharmaceutical advertisements in medical journals: a systematic review. PloS one. 2009;4(7):e6350.

9. Lal A. Information contents of drug advertisements: an Indian experience. Annals of Pharmacotherapy. 1998;32(11):1234-8.

10. Gitanjali B, Shashindran CH, Tripathi KD, Sethuraman KR. Are drug advertisements in Indian edition of BMJ unethical?. BMJ. 1997;315(7106):459. 